\title{
Waste water pollution
}

\section{Editorial}

Pollution of industrial waste water caused by the discharge of harmful chemicals and substances into water, making it unsuitable for consumption and for other purposes. Although 60 to $70 \%$ of the land is covered with water, so water bodies such as lakes, ponds, rivers, reservoirs and watercourses provide us with fresh water, keep it clean, it is a matter of survival, not only for people, but also for all other life forms. Since the industrial revolution, we have achieved many things; our manufacturing process to become more efficient and productive, science has become more sophisticated and our lives have changed. But perhaps nothing comes without a price. All the progress and development seen in past centuries have also brought with them a wide range of problems; water pollution is one of them. Fouling refers to pollution and hazardous waste environmental materials, which lead to a significant change in the quality of the surrounding atmosphere. Pollution of the environment can be classified as air pollution, water pollution and noise. Water pollution means water pollution, which is unfit for consumption and for other purposes. There are essentially five main sources of water pollution from domestic wastewater, agricultural run-off and industrial wastewater, sewage from septic tanks and rainwater. There is a lack of stringent pollution control policies in many countries around the world, particularly in developing and underdeveloped countries. In many countries, policies exist, but the apathy of law enforcement authorities has allowed industries to take these laws for granted and easily circumvent them.

Some industries still rely on old and obsolete technologies that produce more pollutants than modern technologies. Industries essentially try to avoid the high cost of modern or sophisticated technologies by using outdated technologies, although they are known to be less efficient than modern technologies. In many countries, industrial water is not treated adequately before it is discharged into rivers or lakes. This is especially true for small industries that do not have enough capital to invest in pollution control equipment. Unplanned industrial growth contributes to water pollution. Although industrial growth stimulates a country's economy, it degrades the environment, especially when it is unforeseen. Growth can also contribute to limiting waste disposal sites and total disregard for pollution control laws are negative consequences of unplanned industrial growth. The extraction of minerals by mining and drilling causes pollution of industrial water. Extraction and drilling operations render the land unusable for agricultural activities and any accidental leakage can escape into the surrounding water and enter the ocean. Oil spills can pollute land and sea. Waste generated during mining operations can increase the salt and mineral content of water and change its $\mathrm{pH}$. Mine mining pollutes both surface water and groundwater. These wastes generated in various industrial processes can basically achieve these changes, when poured into water bodies. Industrial water pollution can have far-reaching consequences for the ecosystem. Water is used in various industrial processes, coming into contact with toxic substances, heavy metals, organic sludge and even radioactive sludge. So, when such polluted water thrown into the ocean or other bodies of water without any treatment, they become unsuitable for any human and agricultural use. Radioactive sludge deposited on the bottom of bodies of water can remain highly radioactive for many decades and pose a serious health risk to people living nearby.
Volume 3 Issue I - 2017

\author{
Shah Maulin P \\ Division of Applied \& Environmental Microbiology, Enviro \\ Technology Limited, India
}

Correspondence: Shah Maulin P, Industrial Waste Water Treatment, Division of Applied \& Environmental Microbiology, Enviro Technology Limited, India, Email shahmp@beil.co.in

Received: April 17, 2017| Published: April 19, 2017

Nuclear reactors are also a major source of pollution of the heat along with power. Thermal pollution refers to an increase in ambient temperature. This may have an adverse effect on aquatic or marine life, as some organisms are extremely sensitive to small changes in temperature. If the nutrient content of water is undergoing changes can disrupt the delicate balance of the ecosystem. For example, if the content of nutrients increases the water, which is known as eutrophication, may promote water bloom. Algal bloom can deplete oxygen in the water. When algae produce oxygen during the day with photosynthesis, at night, which use oxygen dissolved in water. Water bloom is often followed by death of large amounts of algae, which are decomposed by bacteria using oxygen. This means that the whole process of algae blooms and subsequent bacterial decomposition of algae deplete the dissolved oxygen in the water. Sometimes this process can reduce the content of oxygen in the water to such an extent that it can no longer support aquatic life. Such hypoxic areas of the ocean where marine life cannot survive are known as dead zones. Common industrial pollutants responsible for causing water pollution are sulphur, asbestos, noxious solvents, polychlorinated biphenyls, lead, mercury, nitrates, phosphates, acids, alkali, dyes, pesticides, benzene, chlorobenzene, carbon tetrachloride, toluene and volatile organic chemicals such as sulphur are harmful to marine life, while asbestos is known to be a potential carcinogen. Drinking water contaminated with asbestos may increase the risk of benign colon polyps.

Nitrates and phosphates are essentially found in fertilizers and may contribute to the eutrophication process that can cause dead zones. On the other hand, the presence of high levels of carbon tetrachloride in drinking water may cause problems with the liver. Other industrial pollutants benzene is suspected to be associated with diseases such as anemia and decreased platelet counts and increased risk of cancer. Chemical chlorobenzene found in insecticides and colorants may adversely affect on the liver, kidney and central nervous system. Toluene is substantially pollutant generated by the oil and petroleum industry, which can also affect the liver, kidney and central nervous system. Volatile organic compounds are essentially solvents used in a wide variety of industrial and household products. If not properly disposed of, these chemicals contaminate groundwater. They can cause a variety of health problems such as headaches, nausea, liver and kidney damage and memory. When industrial water pollution, it is difficult to contain, it is not impossible. Greater awareness should be created among the common masses about how water gets polluted, it can be prevented its effects on human health and marine life and how. 
It is not possible to reduce water pollution without public cooperation and cooperation of industrial units. Strict pollution control laws and regulations and their effective implementation have an important role in controlling any kind of pollution. Development of cost-effective pollution control equipment and incentives from the government for installing these devices can encourage industry to take control pollution seriously.

Some industrial wastes are common waste, as well as domestic sewage. Such waste can be easily treated municipal facilities. But some wastes, such as heavy metals, volatile organic compounds and oils and fats need special treatment. Industries can install separate pre-treatment of such hazardous waste. Partially treated waste water may be sent to the local system for further purification. Extensive industries generate large amounts of waste water. These sectors should revise their manufacturing processes to reduce the amount of pollutants and operate their own facilities for treatment on the spot. Industrial wastewater treatment can be performed in three stagesprimary treatment, which includes mechanical processes, biological processes for secondary treatment and tertiary treatment which can be performed using biological, physical and chemical processes. In the primary treatment, pollutants are separated from the water by screening, grinding, flocculation and sedimentation processes. In the secondary treatment, biological methods are used for wastewater treatment. Finally, the waste water is recycled to the tertiary treatment using biological, physical and chemical processes. Thermal pollution on the other hand, can be controlled by creating cooling ponds, or by using a cooling tower. The cooperation of citizens and industrial units, proper enforcement of legislation and the availability of effective and cheaper pollution control techniques are essential prerequisites for the success of such legislation.

\section{Conclusion}

With genetic engineering technology, some of the activities of microbial cultures are now a reality. This has led to new approaches to the treatment of waste. New microbial species that are genetically modified and that cannot be found in nature may be patentable. The accumulation of research and study, as well as the results of the current state of the art application of biotechnology is the treatment of waste will lead to a more efficient system.

\section{Acknowledgements}

None.

\section{Conflict of interest}

The author declares no conflict of interest. 